\title{
CAPACIDADES DINÂMICAS E INTERNACIONALIZAÇÃO DA INOVAÇÃO: O CASO SIEMENS BRASIL
}

\author{
Antonio de Sant'Anna Limongi França, Emerson Antonio Maccari, Priscila Rezende Da Costa ${ }^{1}$ \\ Escola Politécnica da Universidade de São Paulo - USP, São Paulo, (Brasil) \\ Universidade Nove de Julho - UNINOVE, São Paulo, (Brasil)
}

DETALHES DO ARTIGO
Artigo Convidado:
Recebido: 26 de junho de 2018
Aceito: 17 de dezembro de 2018
Disponível online: 01 de janeiro de 2019
Editor Científico
Ilan Avrichir

\section{Palavras-chaves:}

Internacionalização

Capacidades Dinâmicas

Subsidiária

Multinacional

\begin{abstract}
RESUMO
O objetivo geral foi analisar como o processo de desenvolvimento de capacidades dinâmicas pode ser potencializado pelas práticas de internacionalização da inovação que incluem, especificamente: (a) a autonomia em P\&D concedida à subsidiária de uma multinacional, (b) as atribuições tecnológicas delegadas à subsidiária de uma multinacional, (c) a transferência reversa de ativos do conhecimento da subsidiária para a matriz e demais subsidiárias estrangeiras de uma multinacional e (d) a ambidesteridade (funções de adaptação e alinhamento) exercida pela subsidiária de uma multinacional. Para tal, foi realizada uma pesquisa qualitativa e adotou-se como método o estudo do caso da Siemens Brasil. De forma específica, analisou-se em profundidade os mecanismos e interfaces do desenvolvimento das seguintes inovações da Siemens Brasil: (1) Transformador Subterrâneo a Seco DrySub, (2) Sistema Smart Grid de gestão de energia, (3) Sistema de Posicionamento Dinâmico de Plataformas Marítimas e (4) Contatores Digitais. Os achados da pesquisa revelam contribuições científicas relevantes no que tange à compreensão dos fundamentos e dos processos chave da capacidade dinâmica de desenvolvimento tecnológico local de uma subsidiária, bem como as sinergias perante às práticas de internacionalização da inovação de uma multinacional.
\end{abstract}

\section{INTRODUÇÃO}

A visão baseada em recursos (VBR) procura fazer a ligação entre a sustentabilidade da vantagem competitiva e a exploração e desenvolvimento de recursos tangíveis e intangíveis (Penrose, 1959; Prahalad \& Hamel, 1990; Teece, 1980, 1982, 1986; Peteraf, 1993; Teece, Pisano \& Shuen, 1997).

A perspectiva fundamental desta visão está em destacar a possibilidade de a empresa desenvolver vantagem competitiva (sustentável), não com base em restrições deliberadas (poder de mercado ou eficiência) e legais (direitos de propriedade bem definidos), mas em restrições complexas (a auto-reprodução dos recursos pela empresa em si é tão difícil quanto à imitação pelos competidores, porque eles são sutis e difíceis de entender) e tácitas (dificuldade de codificar e transferir conhecimento).

\footnotetext{
${ }^{1}$ Contato do autor - E-mail: priscilarezende@ yahoo.com.br
}

De modo geral, a VBR sugere que a vantagem competitiva sustentável requer, além da exploração dos recursos e capacidades internas e externas, o desenvolvimento (investimento, renovação e alavancagem) de novos recursos e capacidades (Prahalad \& Hamel, 1990; Collis \& Montgomery, 1995; Teece et al., 1997) ou a combinação de habilidades (competências/ capacidades) e recursos únicos (essenciais/dinâmicos) que construa, mantenha e realce as vantagens distintivas e difíceis de imitar. Assim, o interesse da VBR é ligar o entendimento da vantagem competitiva e das dinâmicas da vantagem competitiva às características dos recursos e como estas características mudam ao longo do tempo.

A gestão contínua e sistematizada dos recursos por parte das multinacionais e suas subsidiárias também abre espaço para discussão dos preceitos da capacidade dinâmica que inclui a capacidade com a qual se 
identifica a necessidade ou oportunidade de mudança, formula a resposta para tal necessidade ou oportunidade e implementa uma linha de ação (Teece et al., 1997). Nem todas as capacidades dinâmicas estão relacionadas a essas três funções. Na verdade, as capacidades dinâmicas servem a diferentes propósitos, estão sempre relacionadas a mudanças e permitem que as empresas entrem em novos negócios ou ampliem os negócios existentes por meio do crescimento interno, aquisições e parcerias estratégicas, enquanto outras ajudam a empresa a criar novos produtos e processos de produção e promover crescimento rentável (Eisenhardt \& Martin, 2000).

O objetivo geral foi analisar como o processo de desenvolvimento de capacidades dinâmicas foi potencializado pelas práticas de internacionalização da inovação que se destacaram nos estudos realizados e que incluem, especificamente: (a) a autonomia em P\&D concedida à subsidiária de uma multinacional, (b) as atribuições tecnológicas delegadas à subsidiária de uma multinacional, (c) a transferência reversa de ativos do conhecimento da subsidiária para a matriz e demais subsidiárias estrangeiras de uma multinacional e (d) a ambidesteridade (funções de adaptação e alinhamento) exercida pela subsidiária de uma multinacional, ou mesmo, pela matriz em relação à subsidiária.

A relevância do artigo é justificada por suas contribuições científicas no que tange à compreensão dos fundamentos e dos processos chave da capacidade dinâmica de desenvolvimento tecnológico local de uma subsidiária e suas sinergias perante as práticas de internacionalização da inovação, considerando ainda a diversificação de decisões e de oportunidades analisadas nos diferentes casos de inovação observados.

Utilizou-se como caso prático um grupo empresarial multinacional, que tem no Brasil uma subsidiária atuante, não só localmente, mas no contexto internacional da corporação. No âmbito da empresa escolhida, tratou-se de casos múltiplos, pois foram analisados os caminhos percorridos por diferentes casos de inovação em diferentes linhas de produtos.

A empresa pesquisada foi a Siemens Brasil, uma subsidiária de empresa multinacional estrangeira que é referência em inovação no país em diferentes setores de mercado, com destaque para o setor de equipamentos e sistemas de geração e transmissão de energia elétrica. Tal variedade de atuação da empresa permitiu o devido aprofundamento do estudo das capacidades dinâmicas em contexto de casos múltiplos que harmonizam os diversos interesses e objetivos estratégicos em um grupo multinacional e sua subsidiária local, representando uma complexidade de situações e de decisões que contribuem de modo relevante para a atualização teórica do capo de estudos a que se propôs o autor deste trabalho, a saber, a questão das capacidades dinâmicas em âmbito de empresa multinacional com subsidiária local.

Em relação à estrutura do artigo, a seção 2 apresenta uma reflexão teórica sobre capacidades dinâmicas e práticas de internacionalização da inovação. Na seção 3 constam os aspectos metodológicos, incluindo o detalhamento do método, do instrumento de coleta de dados adotado e a estrutura do protocolo de pesquisa. Já a seção 4 concentra a análise descritiva e propositiva do processo de desenvolvimento de capacidades dinâmicas na Siemens Brasil, bem como os mecanismos e interfaces do desenvolvimento das seguintes inovações: (1) Transformador Subterrâneo a Seco DrySub, (2) Sistema Smart Grid de gestão de energia, (3) Sistema de Posicionamento Dinâmico de Plataformas Marítimas e (4) Contatores Digitais. Além disso, são analisadas as práticas de internacionalização da inovação adotadas pela Multinacional no contexto brasileiro. A seção final sintetiza os resultados alcançados e esboça as limitações do estudo e as possibilidades de estudos futuros.

\section{CAPACIDADE DINÂMICA E A INTERNACIONALIZAÇÃO DA INOVAÇÃO}

Capacidade dinâmica deve ser entendida como a capacidade de uma organização de criar, ampliar ou modificar, propositalmente, a sua base de recursos (HELFAT et al., 2007). A "base de recursos" de uma organização inclui ativos (ou recursos) tangíveis, intangíveis e humanos, assim como as capacidades que a organização possui, controla ou tem acesso por meio de parcerias. A palavra "capacidade" se refere à habilidade de desempenhar uma mudança na base de recursos de uma organização, implicando em um potencial desempenho adequado. $O$ termo "capacidade" também consiste de uma atividade padronizada que possa ser executada de forma confiável em certa extensão (Winter, 2003).

O termo "propositalmente" também tem um significado específico e indica que as capacidades dinâmicas refletem algum grau de intenção, o que as distinguem das rotinas organizacionais, as quais não apresentam intenção. $\mathrm{O}$ atributo de intencionalidade diferencia, portanto, o aspecto padronizado das capacidades dinâmicas de atividades organizacionais corriqueiras e também distingue capacidades dinâmicas de acidente ou sorte (Helfat et al., 2007).

O que distingue uma capacidade dinâmica de uma operacional é que a primeira permite "criar, ampliar ou 
modificar" a base de recursos de uma organização, enquanto a segunda pertence às operações correntes de uma organização. A criação de recursos em uma organização inclui a obtenção de novos recursos por meio de aquisições, parcerias e atividades inovadoras e empreendedoras. A ampliação promove o crescimento de um negócio em andamento. Já a modificação da base de recursos inclui uma resposta às mudanças no ambiente externo, alterando o negócio (Helfat et al., 2007).

A definição de capacidade dinâmica de Helfat et al. (2007) incorpora ainda os aspectos pesquisa e seleção. A criação de recursos por meio de aquisições, por exemplo, envolve fundamentalmente pesquisa e seleção de candidatos à aquisição. A criação de recursos por meio do desenvolvimento de novos produtos de forma similar envolve pesquisa e seleção de novos produtos a serem introduzidos. Uma lógica similar se aplica à pesquisa e seleção por meio de parcerias e a qualquer número de outras capacidades dinâmicas diretamente direcionadas à criação de recursos. A ampliação da base de recursos atuais também requer uma importante decisão de seleção, no que diz respeito a aumentar ou não os ativos e capacidades atuais. Além disso, a modificação de uma base de recurso requer pesquisa e seleção de quaisquer modificações. Como parte da modificação dos recursos, uma empresa pode escolher destruir parte de sua base de recursos existente vendendo, fechando ou descartando-a.

Teece (2007), com um propósito mais analítico, expandiu o conceito das Capacidades Dinâmicas organizacionais em diversos processos que mobilizam os recursos de uma empresa, os quais denominou "meta-Capacidades Dinâmica". São os recursos humanos, com suas competências individuais, inseridos em uma estrutura organizacional (que possui história, cultura, etc.), que serão os principais atores internos. Tudo isso, tendo em vista que as Capacidades Dinâmicas são o "resultado" desta mobilização de processos, recursos e competências disponíveis na empresa e no seu ecossistema. Os processos chave das capacidades dinâmicas propostas por Teece (2007) são:

Tabela 1. Processos chave das Capacidades Dinâmicas e seus elementos fundamentais.

\begin{tabular}{|c|c|c|}
\hline $\begin{array}{l}\text { Processos } \\
\text { chave }\end{array}$ & Descrição & Elementos fundamentais \\
\hline $\begin{array}{l}\text { Mapeamento do } \\
\text { ambiente }\end{array}$ & $\begin{array}{l}\text { Sistemas de } \\
\text { análise para } \\
\text { identificar, } \\
\text { filtrar, calibrar } \\
\text { e aprender } \\
\text { diante das } \\
\text { oportunidades. }\end{array}$ & $\begin{array}{l}\text { 1. Processos internos para direcionar pesquisa e desenvolvimento e selecionar } \\
\text { novas tecnologias. } \\
\text { 2. Processos para explorar fornecedores e complementadores de inovação. } \\
\text { 3. Processos para explorar desenvolvimentos exógenos em ciência e } \\
\text { tecnologia. } \\
\text { 4. Processos para identificar os segmentos de mercado alvo, as mudanças das } \\
\text { necessidades dos clientes e inovações. }\end{array}$ \\
\hline $\begin{array}{l}\text { Aproveitamento } \\
\text { das } \\
\text { oportunidades }\end{array}$ & $\begin{array}{l}\text { Estruturas, } \\
\text { processos, } \\
\text { modelos e } \\
\text { incentivos para } \\
\text { aproveitar as } \\
\text { oportunidades. }\end{array}$ & $\begin{array}{l}\text { 1. Delimitação da solução para o cliente e do modelo de negócio, envolvendo } \\
\text { a seleção da tecnologia e da arquitetura produto, projetar receitas de } \\
\text { arquiteturas, selecionar clientes-alvo, conceber mecanismos para capturar } \\
\text { valor. } \\
\text { 2. Seleção de protocolos de tomada de decisão, que envolve o reconhecimento } \\
\text { dos pontos de inflexão e de complementaridade. } \\
\text { 3. Seleção dos limites da empresa, para gerir e controlar plataformas } \\
\text { complementares, que envolve a calibragem da especificidade dos ativos, o } \\
\text { controle dos estrangulamentos dos ativos, avaliar a apropriação e } \\
\text { reconhecer, gerenciar e capturar economias coespecializadas. } \\
\text { 4. Construir lealdade e compromisso, envolvendo a demonstração de } \\
\text { liderança, o estabelecimento de uma comunicação eficaz e o } \\
\text { reconhecimento de fatores não econômicos, valores e cultura. }\end{array}$ \\
\hline $\begin{array}{l}\text { Gestão de } \\
\text { ameaças e } \\
\text { transformações }\end{array}$ & $\begin{array}{l}\text { Alinhamento e } \\
\text { realinhamento } \\
\text { contínuo de } \\
\text { ativos tangíveis } \\
\text { e intangíveis. }\end{array}$ & $\begin{array}{l}\text { 1. Descentralização e decomposição, que aborda a adoção de estruturas } \\
\text { flexíveis, adoção de estratégias de inovação aberta e desenvolver, integrar e } \\
\text { coordenar competências. } \\
\text { 2. Governança, que envolve o alcance de alinhamento, a minimização de } \\
\text { problemas de agência e o bloqueio de dissipação de renda. } \\
\text { 3. Coespecialização, que envolve o gerenciamento estratégico da forma como } \\
\text { a combinação de ativos reforça a criação de valor. } \\
\text { 4. Gestão do conhecimento, que aborda aprendizagem; transferência de } \\
\text { conhecimentos, alcance e integração de know-how e proteção da } \\
\text { propriedade intelectual. }\end{array}$ \\
\hline
\end{tabular}

Fonte: Adaptado de Teece (2007). 
Para Teece (2014), é fundamental a compreensão das capacidades dinâmicas como fator determinante para a competitividade das empresas multinacionais. Tais capacidades dizem respeito, não apenas às especialidades técnicas das subsidiárias ou das controladoras, mas vai além, incluindo as capacidades estratégicas, gerenciais e organizacionais das partes envolvidas, sendo cada caso um caso, não havendo um padrão pré-definido de globalização ou de regionalização, a depender de cada situação estudada e dos caminhos que levam à inovação e à sempre renovada competitividade das empresas.

Portanto, constata-se que a referida abordagem é especialmente relevante, pois mais importante do que o estoque atual de recursos da matriz é a capacidade de acumular, combinar e criar novos recursos entre as subsidiárias e seus parceiros tecnológicos, especialmente, se essas capacidades assumem intencionalidade estratégica, contribuem para a geração de mudanças distintivas e são capazes de continuamente gerar vantagem competitiva sustentável às multinacionais em temas como desenvolvimento de novos produtos e processos.

A partir das discussões das capacidades dinâmicas, pode-se entender as multinacionais como sistemas coordenados ou redes que criam atividades de valor, algumas realizadas dentro da hierarquia da empresa, outras realizadas a partir de relacionamentos contratuais e sociais (Doz, Santos \& Williamson, 2001; Dunning \& Lundan, 2008). Dessa forma, uma multinacional não deve ser definida apenas pela extensão das suas instalações estrangeiras de produção, mas pela soma total de todas as suas atividades internas e externas que criam valor (Dunning, 2006; Andersson, Forsgren \& Holm, 2002). Diante disso, as multinacionais estão mudando suas estruturas para redes abertas e flexíveis, com subsidiárias que criam e compartilham conhecimento em contextos locais e globais (Cantwell, Dunning \& Lundan, 2010).

Esta estrutura requer da multinacional a disseminação e a institucionalização da gestão das relações de cooperação e a criação e integração contínua dos conhecimentos desenvolvidos na matriz, nas subsidiárias e nas parcerias em contextos locais e globais (Mudambi, 2008; Gnyawali, Singal \& Mu, 2009; Dunning \& Lundan, 2010).

Em resposta à necessidade de equilibrar a integração global e a resposta local, as subsidiárias estrangeiras devem desempenhar um papel de destaque na criação de conhecimentos valiosos à multinacional com um todo (Phene \& Almeida, 2008).
Nesse contexto, um dos principais problemas de gestão refere-se ao equilíbrio entre mecanismos de coordenação e fluxos de conhecimento da subsidiária para a matriz, conhecida como a transferência reserva de ativos do conhecimento (Frost \& Zhou, 2005; Yang, Mudambi \& Meyer, 2008; Eden, 2009).

A implantação de mecanismos de coordenação no relacionamento matriz-subsidiária, como a descentralização da tomada de decisão e os mecanismos de comunicação, devem ser vistos como um antecedente fundamental para a transferência reversa de ativos do conhecimento (Rabbiosi, 2011). Nesse sentido, há um consenso na literatura sobre as principais práticas de internacionalização da inovação que podem determinam a coordenação e integração global das subsidiárias das multinacionais, sendo elas: a autonomia da subsidiária (Birkinshaw, Hood \& Young, 2005), as atribuições da subsidiária (Cantwell \& Mudambi, 2005; Noorderhaven \& Harzing, 2009), a transferência reversa de ativos do conhecimento (Ambos \& Schlegelmilch, 2007; Keupp, Palmié \& Gassmann, 2011), e ambidesteridade (Birkinshaw \& Gibson, 2004).

Destaca-se que a autonomia da subsidiária é dividida em duas categorias distintas, a estratégica e a operacional (Bartlett \& Ghoshal, 1989; Birkinshaw, 1996; Nobel \& Birkinshaw, 1998). Autonomia estratégica é definida como a capacidade da subsidiária de definir a sua própria agenda, enquanto a autonomia operacional é definida como a capacidade da subsidiária de gerenciar as atividades previamente designadas pela corporação (Bailyn, 1985). Autores como Keupp et al. (2011) e Ambos e Schlegelmilch (2007) argumentam que a autonomia estratégica terá implicações negativas para o desempenho da subsidiária por dois motivos. Primeiro, porque a integração de subsidiárias altamente autônomas tende a ser menor devido à dificuldade de coordenação, levando ao isolamento das referidas filiais (Cantwell \& Mudambi, 2005); segundo, porque os recursos das subsidiárias autônomas são potencialmente menos compatível com o estoque de recursos da rede de negócios da multinacional, portanto, os incentivos e investimento adicionais tendem a ser mais contidos, o que afetará negativamente o seu poder de barganha e o seu desempenho (Frost, Birkinshaw \& Ensign, 2002).

O grau de autonomia operacional de uma subsidiária se reflete no alcance e na extensão das tarefas predefinidas pela corporação. Uma subsidiária com autonomia operacional pode tomar suas próprias decisões sobre a cooperação com empresas e organizações externas, promovendo o reconhecimento 
e a utilização dos recursos disponibilizados pelos sistemas locais de inovação. Assim, quanto maior a autonomia operacional de uma subsidiária, maior será a sua capacidade para explorar fontes externas de inovação e melhorar a sua base de recursos e o seu desempenho. Cabe também destacar que a autonomia operacional deve oferecer aos colaboradores das subsidiárias a oportunidade de abordar os problemas de forma criativa, estimulando a criatividade e a inovação organizacional (Ambos \& Schlegelmilch, 2007).

Portanto, é relevante compreender como a autonomia em P\&D concedida à subsidiária pode potencializar as capacidades dinâmicas, sendo oportuna a apresentação da seguinte indagação:

101: A autonomia em P\&D concedida à subsidiária potencializa o desenvolvimento de capacidades dinâmicas?

Sobre as atribuições de uma subsidiária, quando delegadas pela matriz da multinacional de forma estratégica, implica que a subsidiária realizará certas atividades em nome da corporação como um todo, implicando em responsabilidades internacionais ao invés de apenas locais, considerando, por exemplo, padrões internacionais de qualidade e de especificações, quando for o caso. As capacidades dinâmicas construídas poderão ser de relevância local, corporativa, havendo situações nas quais a inovação primeiramente atende a uma necessidade local, podendo expandir sua relevância a outras subsidiárias ou mesmo à corporação como um todo. Ao conduzir atividades de impacto internacional, uma subsidiária poderá receber investimentos adicionais (Frost et al., 2002) e desenvolver competências difíceis de imitar, o que afetará positivamente o seu poder de barganha (Mudambi \& Navarra, 2004; Bouquet \& Birkinshaw, 2008) e o seu desempenho (Andersson et al., 2002). Portanto, é relevante analisar como as atribuições tecnológicas delegadas à subsidiária podem potencializar as capacidades dinâmicas. Indaga-se:

102: As atribuições tecnológicas delegadas à subsidiária potencializam o desenvolvimento de capacidades dinâmicas?

A transferência de ativos do conhecimento está especialmente relacionada ao surgimento de uma base de conhecimento global compartilhada, gerando reciprocidade e um fluxo frequente de conhecimento entre as subsidiárias (Monteiro, Arvidsson \& Birkinshaw, 2008). Ativos do conhecimento abrangem as informações, know-how, práticas, capacidades, tecnologias e produtos (Yang et al., 2008) que, ao serem transferidos, podem estimular o desenvolvimento de competências que afetam o desempenho de uma subsidiária (Mudambi \& Navarra, 2004), que por sua vez, podem aumentar o seu poder de barganha e de influência estratégica dentro da rede de negócios da multinacional. Portanto, é relevante compreender como a transferência reversa de ativos do conhecimento da subsidiária para a matriz e demais subsidiárias estrangeiras pode potencializar as capacidades dinâmicas. Daí a indagação:

103: A transferência reversa de ativos do conhecimento da subsidiária para a matriz e demais subsidiárias estrangeiras potencializa o desenvolvimento de capacidades dinâmicas?

Em relação à ambidesteridade, Birkinshaw e Gibson (2004) definem essa abordagem como sendo as funções de identificação de oportunidades (que permitem adaptabilidade) e a racionalização de recursos e processos (que determinam o alinhamento), buscando criar mais valor. Em outras palavras, a capacidade de perceber oportunidades ambientais é definida pelos autores como sendo a função de adaptabilidade. Já a capacidade de identificar e mobilizar internamente seus recursos para aproveitar as oportunidades externas refere-se à função de alinhamento. Dessa forma, é relevante compreender como as funções de adaptação e alinhamento (ambidesteridade) podem potencializar as capacidades dinâmicas. São pertinentes as indagações:

104: A função de adaptação exercida pela subsidiária potencializa o desenvolvimento de capacidades dinâmicas?

105: A função de alinhamento exercida pela subsidiária potencializa o desenvolvimento de capacidades dinâmicas?

Por fim, vale frisar que a internacionalização da inovação em uma multinacional dependerá cada vez mais da intensa melhora da capacidade de articular o conhecimento que se encontra disperso e inutilizado em sua rede de subsidiárias e parceiros tecnológicos (Altmann, 2005; Manolopoulos, Söderquist \& Pearce, 2011; Lehrer, Asakawa \& Behnam, 2011; Sirkin, Hemerling \& Bhattacharya, 2008; Yiu, Lau \& Bruton, 2007). O desafio primordial é, portanto, institucionalizar e efetivar o gerenciamento da capacidade dinâmica de desenvolvimento tecnológico local nas subsidiárias de forma sistematizada e sinérgica (Criscuolo \& Narula, 2007; Cantwell \& Piscitello, 2007; Marin \& Bell, 2010).

\section{METODOLOGIA DE PESQUISA}

A pesquisa foi qualitativa e assumiu natureza descritiva. Segundo Richardson (1999), a pesquisa qualitativa é caracterizada como uma tentativa de compreensão detalhada dos significados e das 
características situacionais apresentadas pelos entrevistados. Para Flick (2009) a pesquisa qualitativa é de particular relevância ao estudo das relações sociais devido à pluralização das esferas da vida. Vieira (2004) reforça que o método qualitativo tem como relevante característica a observação do fenômeno de modo total, tratado individualmente, com profundidade, permitindo ao pesquisador construir a realidade a partir das suas observações específicas.

Adotou-se como método o estudo em profundidade do caso Siemens Brasil, no qual foram analisados as capacidades dinâmicas e a internacionalização da inovação, bem como os mecanismos e interfaces do desenvolvimento das inovações: (1) Transformador subterrâneo a seco (DrySub): desenvolvimento conjunto fornecedorcliente; (2) Sistema smart grid de gestão de energia: desenvolvimento entre a empresa, suas subsidiárias ao redor do mundo e um Centro de P\&D em Universidade local; (3) Sistema de posicionamento dinâmico de plataformas marítimas: desenvolvimento que integrou agencia de desenvolvimento, universidade, centro de pesquisa e empresas de diferentes origens; e (4) Contatores Digitais: desenvolvimento conjunto entre empresas parceiras. Os dados utilizados na pesquisa são de natureza primária (Martins, 2006) e foram coletados por meio de entrevistas semi-estruturadas (Gil, 2002), as quais são bastante adequadas para a obtenção de informações sobre o que as pessoas sabem, creem, esperam, sentem ou desejam, pretendem fazer, fazem ou fizeram. As entrevistas foram realizadas como o Diretor de Tecnologia e Inovação da Siemens Brasil e com Especialistas em Inovação que atuam na empresa, totalizando 12 entrevistas.

Miles e Huberman (1984) citam que, a análise de dados qualitativos em um estudo de caso complexo exige a utilização de técnicas que facilitem a compreensão, síntese e o devido sumário dos resultados e sugerem a criação de meta-matriz que possibilite sintetizar e agrupar os dados em clusters. Dessa forma, os dados da pesquisa foram sintetizados e agrupados em clusters, conforme sugerem Miles e Huberman (1984) e alinhados à (1) a autonomia em P\&D concedida à subsidiária, (2) as atribuições tecnológicas delegadas à subsidiária, (3) a transferência reversa de ativos do conhecimento da subsidiária para a matriz e demais subsidiárias estrangeiras, e (4) a função de adaptação exercida pela subsidiária e (5) a função de alinhamento exercida pela subsidiária. Quanto ao protocolo de pesquisa adotado, destacam-se no quadro a seguir os clusters de análise e as perguntas de pesquisa, bem como a base teórica correspondente.

Tabela 2. Protocolo de pesquisa.

\begin{tabular}{|c|c|c|}
\hline Clusters & Tópicos que direcionaram a coleta dos dados primários & Base teórica \\
\hline $\begin{array}{l}\text { (1) Autonomia em } \\
\text { P\&D concedida à } \\
\text { subsidiária }\end{array}$ & $\begin{array}{l}\text { A subsidiária dispõe de autonomia operacional em P\&D? } \\
\text { A subsidiária dispõe de autonomia estratégica em P\&D? } \\
\text { A subsidiária dispõe de autonomia para criar ativos } \\
\text { específicos às parcerias tecnológicas? }\end{array}$ & $\begin{array}{l}\text { Ambos e Schlegelmilch (2007), } \\
\text { Bartlett e Ghoshal (1989), } \\
\text { Birkinshaw (1996), Frost } \text { et al. } \\
\text { (2002), Helfat } \text { et al. (2007), } \\
\text { Keupp et al. (2011) e Nobel e } \\
\text { Birkinshaw (1998). }\end{array}$ \\
\hline $\begin{array}{l}\text { (2) Atribuições } \\
\text { tecnológicas } \\
\text { delegadas à } \\
\text { subsidiária }\end{array}$ & $\begin{array}{l}\text { Que atribuições são delegadas à subsidiária no que tange o } \\
\text { desenvolvimento de inovações locais? } \\
\text { Que atribuições são delegadas à subsidiária no que tange o } \\
\text { desenvolvimento de inovações globais? } \\
\text { As atribuições assumidas pela subsidiária nas parcerias } \\
\text { proporcionam acesso à recursos complementares? }\end{array}$ & $\begin{array}{l}\text { Andersson et al. (2002), } \\
\text { Bouquet e Birkinshaw (2008), } \\
\text { Cousins et al. (2006), Frost et al. } \\
\text { (2002), Gulati (1995), Mudambi } \\
\text { e Navarra (2004), Petruzzelli } \\
\text { (2011), Powell et al. (1996) e } \\
\text { Teece (1988). }\end{array}$ \\
\hline $\begin{array}{l}\text { (3) Transferência } \\
\text { reversa de ativos do } \\
\text { conhecimento da } \\
\text { subsidiária para a } \\
\text { matriz e demais } \\
\text { subsidiárias } \\
\text { estrangeiras }\end{array}$ & $\begin{array}{l}\text { Como ocorre a transferência reversa de ativos do } \\
\text { conhecimento da subsidiária para a matriz? } \\
\text { Como ocorre a transferência reversa de ativos do } \\
\text { conhecimento da subsidiária para demais subsidiárias } \\
\text { estrangeiras? } \\
\text { Como a subsidiária organiza e assimila do novo conhecimento } \\
\text { gerado nas parcerias? }\end{array}$ & $\begin{array}{l}\text { Cohen e Levinthal (1990), Dyer } \\
\text { (1996), Grant (1996), Helfat et } \\
\text { al (2007), Monteiro et al. } \\
\text { (2008), Mudambi e Navarra } \\
\text { (2004) Yang et al. (2008). }\end{array}$ \\
\hline $\begin{array}{l}\text { (4) Ambidesteridade } \\
\text { exercida pela } \\
\text { subsidiária }\end{array}$ & $\begin{array}{l}\text { Como se dá o mapeamento das oportunidades tecnológicas e } \\
\text { mercadológicas? } \\
\text { Como ocorre a identificação e mobilização de recursos de } \\
\text { inovação internos e externos necessários para aproveitar as } \\
\text { oportunidades? } \\
\text { Que mecanismos de governança são utilizados para identifica } \\
\text { e mobilizar recursos de inovação? }\end{array}$ & $\begin{array}{l}\text { Birkinshaw e Gibson (2004), } \\
\text { Debackere e Veugelers (2005), } \\
\text { Dyer (1996), Gulati (1995), } \\
\text { Helfat et al (2007), Williamson } \\
\text { (1991), Zaheer } \text { et al. (1998) e } \\
\text { Zollo et al. (2002). }\end{array}$ \\
\hline
\end{tabular}

Fonte: Autores. 


\section{ANÁLISE DOS RESULTADOS}

Neste capítulo tratar-se-á incialmente da apresentação da empresa e de seu âmbito de atuação. A seguir haverá explicação sobre as estratégias de crescimento e de aproveitamento das capacidades dinâmicas das subsidiárias com a corporação e mesmo entre si. As informações foram obtidas com a direção de tecnologia e inovação da empresa. Em sequência serão resumidos casos específicos, os quais foram discutidos com os técnicos e especialistas envolvidos em cada caso analisado.

\section{A Siemens}

A Multinacional Siemens iniciou suas atividades em 1847, na Alemanha, sua sede global, de onde se expandiu para 190 países, cujas principais áreas de atuação são: saúde, energia e indústria e, com participação ainda muito pequena, na área de infraestrutura e cidades. Destaca-se que os principais investimentos globais em P\&D da multinacional em 2013 foram: 4,1 bilhões de Euros (5,7\% da receita); 29 mil colaboradores envolvidos em P\&D no mundo; 140 centros de pesquisa e desenvolvimento localizados em 30 países; e 60 mil patentes ativas (SIEMENS, 2014).

Com 7.133 colaboradores no Brasil, a empresa obteve um faturamento líquido de 5.041 bilhões de reais em 2014, sendo que o seu conglomerado nacional é atualmente composto pela sede, 13 escritórios Regionais, 12 fábricas e 7 núcleos de P\&D organizados nas seguintes áreas temáticas: Transformadores, Painéis de Média-Tensão, Turbinas, Capacitores e Automação de Energia (Jundiaí/SP); Automação e Controle e Sistemas de Informação (São Paulo/SP); Disjuntores (Manaus/AM); Interruptores, Tomadas e Sensores (Canoas/RS); Soluções para Smart Grids (redes inteligentes, em Curitiba/PR e Belo Horizonte/MG); e Eletromedicina (Joinville/SC) (SIEMENS, 2014).

\section{Estratégias Adotadas e a Construção de Capacidades Dinâmicas}

Com foco no fortalecimento da operação local, a Siemens Brasil destaca a nacionalização dos produtos e sistemas do setor de Energia, que está acima de 70\%. Em complemento, a empresa abriu no país oito novas fábricas desde 2008. Já a Divisão de Óleo e Gás tornou-se um Centro de Competência Mundial.
Outro dado relevante refere-se à inauguração do Centro de P\&D no Rio de Janeiro, ocorrido em fins de 2012, contando com 800 profissionais, entre pesquisadores e engenheiros, com atuação em controle avançado de software, óleo e gás e tecnologias submarinas.

No que tange a integração dos centros de $P \& D$ nacionais e internacionais da Siemens, destaca-se o mecanismo de compartilhamento de informações e conhecimentos disponível para todos os inscritos em cada grupo de pesquisa, incluindo questões relativas a problemas e soluções de casos ocorridos em todos os países de atuação da multinacional. Trata-se do portal denominado TECHNOWEB que segundo o Diretor de Tecnologia e Inovação, é "um mecanismo de gestão do conhecimento, ou seja, uma plataforma virtual, acessível a todos os colaboradores da Siemens, na qual todos podem trocar experiências, conhecimentos e informações através de comunidades temáticas criadas pelos próprios usuários. Após se inscrever em uma determinada comunidade de interesse, o colaborador passa a ter acesso a todo o conteúdo discutido em torno daquele tema e pode também estimular o início de debates. Em caso de necessidades urgentes para solução de problemas e dúvidas, é possível também enviar "Urgent Requests" a todos os participantes da plataforma, para que estes colaborem com o tema. Vale destacar que a plataforma é utilizada também para a localização de partes e peças de produtos de gerações antigas, de rara utilização.

Cabe frisar que embora o TECHNOWEB seja um mecanismo bastante difundido, ele não é utilizado como padrão único de captação de novas ideias ou para a integração de grupos em novos desenvolvimentos. O Diretor de Tecnologia e Inovação ressalta que não existi um padrão internacional para a captação de novas ideias e para a definição de novos desenvolvimentos que deva ser seguido pela Siemens Brasil, uma vez que novas ideias podem emergir a partir das oportunidades de mercado e das interações com clientes, instituições científicas e tecnológicas (ICTS), subsidiárias estrangeiras e matriz.

Apesar de não existir um padrão global para a geração de novos produtos e processos, a Siemens promove estudos sobre o futuro e as possibilidades de atuação da empresa. Para tal, foi desenvolvido o 
mecanismo denominado Pictures of the Future (PoF), que é uma metodologia interna própria de geração e análise de cenários. Segundo o Diretor de Tecnologia e Inovação "o PoF é um dos principais mecanismos estratégicos da empresa, dedicado a medir tanto o desempenho do portfólio e o alcance das estratégias atuais, bem como derivar, a partir de tendências estabelecidas, quais as tecnologias devem ter seu desenvolvimento priorizado". Vale pontuar que a aplicação do PoF envolve especialistas internos e externos de vários países do mundo e aborda aspectos tecnológicos, socioeconômicos, ambientais, entre outros. A partir dos cenários que resultam destes estudos, o Diretor de Tecnologia e Inovação destaca que "são derivadas trilhas tecnológicas que a Siemens deverá percorrer, além de oportunidades de negócios e planos de desenvolvimento de produtos que muitas vezes exigirá integrações tecnológicas ou demandará tecnologias disruptivas e também tecnologias cross setoriais".

Em relação aos desenvolvimentos não aderentes às trilhas tecnológicas da Siemens Brasil, seja por estarem fora dos objetivos estratégicos da empresa, seja porque não mostram retorno econômico adequado, a Siemens conta, globalmente, com o departamento Siemens Technology Accelerator (STA), responsável por identificar e implementar estratégias de comercialização para inovações que não atuam no core de negócios da Multinacional. O Diretor de Tecnologia e Inovação informa ainda que "essas estratégias englobam ações como venda e licenciamento de spin-off tecnológicos".

Em relação à aquisição de tecnológicas externas, a Siemens Brasil conta com uma Unidade chamada Technology to Business (TTB) que, segundo o Diretor de Tecnologia e Inovação, está "focada no investimento e incubação de startups de base tecnológica, que possam contribuir para a expansão do portfólio da empresa". Dessa forma, a TTB é responsável por prospectar, analisar e capacitar startups, com potencial de receber investimentos da Siemens. Para a realização de tal objetivo, o TTB conta com especialistas das diversas áreas de atuação global da Multinacional.

No Brasil, a Siemens conta com uma diretoria de Inovação e Tecnologia que, além de ser a gestora do TTB, atua em conjunto com as engenharias das áreas de negócios, realizando projetos de pesquisa e desenvolvimento também com parceiros externos, principalmente institutos de ciência e tecnologia e empresas parceiras.

Sobre a autonomia em P\&D da Siemens Brasil, o diretor de Inovação e Tecnologia explica que a "Siemens é uma multinacional global, sendo assim, as estratégias e trilhas tecnológicas de longo prazo são desenhadas a partir do PoF e, posteriormente, discutidas entre matriz e subsidiárias considerando suas respectivas vocações e atribuições tecnológicas. Depois de definida a agenda estratégica a nível matriz, os desenvolvimentos locais de produtos e processos que levam a inovação são consequência das discussões e decisões de cada setor ou de cada local em que a empresa atua, não havendo centralização nestas definições". O diretor também destaca que "a maioria das inovações da empresa está focada em inovações para clientes. A Siemens trabalha a partir de grandes contratos, sobretudo em projetos de geração/transmissão de energia e infraestrutura. Por esse motivo, muitos de nossos projetos têm um caráter único que deverá atender as demandas específicas de nossos clientes. Um projeto para automação de uma usina hidroelétrica, por exemplo, tem exigências únicas: os equipamentos a serem integrados dificilmente terão as mesmas características, a quantidade de equipamentos a serem integrados e controlados por vezes é singular e o sistema para o qual a energia será fornecida também tem exigências particulares".

A propósito, a Siemens aproveita a vocação das várias localidades em que atua, sendo que o Brasil é centro de competência em algumas áreas de atuação, como, por exemplo, no setor de energia.

Os produtos aqui desenvolvidos têm grande conteúdo de tecnologia local, sendo, depois, incorporados a outros produtos para integração de soluções junto a clientes do mundo todo, formando uma rede global de inovação. O diretor de Inovação e Tecnologia sintetiza as principais atribuições tecnológicas da Siemens Brasil:

a) Em detrimento da sua posição geográfica, a Siemens Brasil tem como atribuição realizar intermediações entre os Centros de P\&D dos Estados Unidos e Alemanha;

b) Prospecção de oportunidades do mercado local com vocação natural para o segmento de energia, com posição diferenciada de investimento em energia entre os BRICs; 
c) Absorção de conhecimento local sólido e compartilhamento com a matriz e demais subsidiárias estrangeiras, contando com a disponibilidade local de profissionais com experiência em desenvolvimento de software SCADA (precursor dos ambientes Smart Grids), com reduzido custo de capacitação e com conhecimento em inglês, além da diminuição do tempo de preparação da equipe e alcance da maturidade; e

d) Estabelecimento de parceiras estratégicas, com acesso a mão de obra qualificada, de nível técnico a PhD, possibilitando uma redução de custos via desenvolvimento de projetos conjuntos, além de acesso facilitado a fomentos públicos, com melhora na posição de custos.

Em relação aos incentivos à inovação, a Siemens Brasil faz uso da Lei do Bem, das subvenções da FINEP e dos financiamentos subsidiados do BNDES. Sobre marcas e patentes, o Diretor de Tecnologia e Inovação destaca que "a Multinacional tem uma estrutura de propriedade intelectual bastante centralizada em sua matriz, por motivos estratégicos e pela demora na concessão de patentes pelo Instituto Nacional da Propriedade Industrial - INPI. Assim, boa parte das patentes, marcas e modelos de utilidade registrados saem do escritório europeu e tem seu depósito feito no Brasil em etapas posteriores. "Nosso mercado é muito dinâmico e atrativo, por esse motivo muitas de nossas tecnologias e marcas são protegidas também aqui e temos também a flexibilidade de discutir com nossa matriz a importância dos registros locais", relatou o diretor da empresa. O diretor acrescenta ainda que "a outra forma de proteção de investimentos em pesquisa e desenvolvimentos se dá através da aquisição e fusão de empresas inovadoras, tanto maduras quanto emergentes".

No que tange as interfaces externas para desenvolvimento e customização de produtos, a Siemens Brasil tem como principais parceiros a matriz alemã, as demais subsidiárias estrangeiras, as instituições científicas e tecnológicos (ICTs) locais que oferecem competências complementares, os fornecedores, os clientes, bem como empresas locais não concorrentes. Como exemplo, cabe destacar a implantação de um Centro de P\&D no país para o desenvolvimento de produtos em parceria com Pontifícia Universidade Católica do Paraná (PUC-PR). Foram alocados trinta pesquisadores, incluindo estudantes e parceiros empresariais, envolvidos em desenvolvimento do núcleo básico de sistemas de energia. A PUC-PR fornece ainda as instalações e a infraestrutura onde são desenvolvidos os módulos de engenharia básica de alguns sistemas da Siemens Brasil, o que possibilita a troca mútua de conhecimentos, experiências, simulações e prototipagem entre a empresa e a universidade.

Destaca-se ainda que durante o desenvolvimento dos sistemas ocorrem interações com as demais subsidiárias estrangeiras, dado que os Centros de P\&D da Siemens nos EUA e na Índia também são utilizados em simulações de situações, a depender da complexidade do caso. Nos EUA existem modelos reduzidos com a mesma complexidade típica das situações reais dos clientes.

Como parte da estratégia de ampliar as funcionalidades das suas inovações, a Siemens Brasil também compra empresas para obter velocidade local na aquisição de determinadas tecnologias, como exemplo destaca-se a compra da empresa brasileira SENERGY, especializada em sistemas de controle e prevenção de fraudes no uso de energia. Vale pontuar que as parcerias estabelecidas pela Siemens Brasil com ICTs, clientes, fornecedores e empresas não concorrentes são tratadas sob contratos de confidencialidade, acompanhadas de sistemas de prevenção e controle do uso de informações computadorizadas.

\section{Casos Práticos de Inovação Estudados e as Capacidades Dinâmicas Construídas}

Com fundamento nas questões descritas na Tabela 2, foi realizada uma avaliação das capacidades dinâmicas de desenvolvimento tecnológico local da Siemens Brasil. Utilizou-se a conceituação de Teece (2007): os processos chave de mapeamento do ambiente, aproveitamento das oportunidades e gestão de ameaças e transformações.

Foram analisados quatro desenvolvimentos locais inovativos em parceria com fontes externas de conhecimento e tecnologia, sendo eles: (1) Transformador subterrâneo a seco DrySub; (2) Sistema Smart Grid de gestão de energia; (3) Sistema de Posicionamento Dinâmico de Plataformas Marítimas; e (4) Contatores Digitais.

As Tabelas 3, 4 e 5 apresentam (na vertical) os processos chave de desenvolvimento das Capacidades Dinâmicas como preconizado por Teece (2007). Já no plano horizontal, resumem as questões específicas sobre os produtos estudados, destacando as parcerias com fontes externas, tanto em relação à Matriz e a outras subsidiárias quanto em conjunto com empresas externas à corporação. 
Tabela 3. Desenvolvimento tecnológico local da Siemens Brasil, considerando o processo de mapeamento do ambiente de Teece (2007).

\begin{tabular}{|c|c|c|c|c|}
\hline \multirow{2}{*}{$\begin{array}{l}\text { Processo chave } \\
\text { ao } \\
\text { desenvolvimento } \\
\text { de Capacidades } \\
\text { Dinâmicas }\end{array}$} & \multicolumn{4}{|c|}{ Desenvolvimentos locais em parceria com fontes externas } \\
\hline & $\begin{array}{l}\text { Transformador } \\
\text { subterrâneo a seco } \\
\text { DrySub }\end{array}$ & $\begin{array}{l}\text { Sistema Smart Grid de } \\
\text { gestão de energia }\end{array}$ & $\begin{array}{l}\text { Sistema de } \\
\text { Posicionamento } \\
\text { Dinâmico de } \\
\text { Plataformas Marítimas }\end{array}$ & Contatores Digitais \\
\hline $\begin{array}{l}\text { Mapeamento do } \\
\text { ambiente }\end{array}$ & $\begin{array}{l}\text { Um cliente e um } \\
\text { especialista da empresa, } \\
\text { ambos com experiência } \\
\text { no assunto e } \\
\text { preocupados com o } \\
\text { melhor desempenho dos } \\
\text { ambientes em que } \\
\text { trabalhavam, durante } \\
\text { uma reunião de trabalho } \\
\text { identificaram lacunas } \\
\text { tecnológicas, } \\
\text { resultando, } \\
\text { posteriormente, em uma } \\
\text { parceria entre Siemens } \\
\text { Brasil, fornecedor e } \\
\text { cliente para o } \\
\text { desenvolvimento do } \\
\text { "Transformador } \\
\text { subterrâneo a seco } \\
\text { DrySub". }\end{array}$ & $\begin{array}{l}\text { Estudos da Siemens } \\
\text { Alemanha (Matriz) } \\
\text { detectaram no mercado } \\
\text { oportunidades } \\
\text { tecnológicas em sistemas } \\
\text { de gestão de energia e } \\
\text { também em função do } \\
\text { acompanhamento da } \\
\text { concorrência de empresas } \\
\text { sediadas na Índia, } \\
\text { resultando, } \\
\text { posteriormente, em uma } \\
\text { parceria entre Siemens } \\
\text { Brasil, matriz, as demais } \\
\text { subsidiárias estrangeiras } \\
\text { e Centro de P\&D em } \\
\text { Universidade local para o } \\
\text { desenvolvimento do } \\
\text { "Sistema Smart Grid de } \\
\text { gestão de energia". }\end{array}$ & $\begin{array}{l}\text { Diretor da empresa } \\
\text { Chemtech, controlada } \\
\text { pela Siemens, identificou } \\
\text { a oportunidade de } \\
\text { desenvolver um sistema } \\
\text { de posicionamento } \\
\text { dinâmico a partir de um } \\
\text { edital de projeto de } \\
\text { pesquisa publicado pela } \\
\text { FINEP, resultando, } \\
\text { posteriormente, em uma } \\
\text { parceria entre Siemens } \\
\text { Brasil, agencia de } \\
\text { desenvolvimento, } \\
\text { universidade, centro de } \\
\text { pesquisa e empresas de } \\
\text { diferentes origens para o } \\
\text { desenvolvimento do } \\
\text { "Sistema de } \\
\text { Posicionamento } \\
\text { Dinâmico de Plataformas } \\
\text { Marítimas". }\end{array}$ & $\begin{array}{l}\text { Um especialista da } \\
\text { Siemens, responsável } \\
\text { pelo suporte técnico ao } \\
\text { departamento de } \\
\text { Marketing de produtos } \\
\text { do setor, percebeu uma } \\
\text { oportunidade } \\
\text { tecnológica a partir do } \\
\text { seu exercício } \\
\text { profissional, } \\
\text { resultando, } \\
\text { posteriormente, em } \\
\text { uma parceria entre } \\
\text { Siemens Brasil e } \\
\text { empresas parceiras } \\
\text { para o } \\
\text { desenvolvimento do } \\
\text { produto "Contatores } \\
\text { Digitais". }\end{array}$ \\
\hline
\end{tabular}

Fonte: Autores.

Tabela 4. Desenvolvimento tecnológico local da Siemens Brasil, considerando o processo de aproveitamento das oportunidades de Teece (2007).

Processo chave Desenvolvimentos locais em parceria com fontes externas

ao

desenvolvimento

de Capacidades

Dinâmicas

Transformador
subterrâneo a seco
DrySub

Sistema Smart Grid de gestão de energia
Sistema de

Posicionamento

Dinâmico de

Plataformas

Marítimas

\section{Contatores Digitais}

A criação e
desenvolvimento do
sistema Smart Grid
ocorreram a partir de
interações da Siemens
Brasil com a matriz, as
demais subsidiárias
estrangeiras e Centro de
P\&D em Universidade
local (PUC - Paraná),
mediante liderança das
equipes de
desenvolvimento de
sistemas da Siemens,
sediados em Jundiaí, São
Paulo. As equipes
internas mantinham
contato direto com os
clientes, cada qual com
suas próprias
especificações de uso e
de integração do sistema.
Observa-se que a origem
do sistema Smart Grid

A criação e

desenvolvimento do produto Contatores Digitais se deu a partir da parceria da Siemens Brasil com uma empresa de porte médio não concorrente que não dispunha de acesso ao mercado internacional, com destacada competência em desenvolvimento de partes mecânicas. No produto utilizou-se laboratórios da Siemens internacional, atendendo a padrões mundiais para a categoria. desenvolvimento do do sistema Smart Grid
A criação e

Sistema de

Posicionamento

Plataformas Marítimas

pela Siemens, mediante parceria de um consultor externo na fase inicial. Em uma segunda etapa foi desenvolvida uma parceria com uma empresa multinacional de origem francesa. foram desenvolvidas soluções técnicas

-




\begin{tabular}{ll}
\hline de P\&D da Siemens & reside no sistema \\
Brasil. & SCADA. \\
\hline
\end{tabular}

Fonte: Autores.

Tabela 5. Desenvolvimento tecnológico local da Siemens Brasil, considerando o processo de gestão de ameaças e transformações de Teece (2007).

\begin{tabular}{|c|c|c|c|c|}
\hline \multirow{2}{*}{$\begin{array}{l}\text { Processo chave } \\
\text { ao } \\
\text { desenvolvimento } \\
\text { de Capacidades } \\
\text { Dinâmicas }\end{array}$} & \multicolumn{4}{|c|}{ Desenvolvimentos locais em parceria com fontes externas } \\
\hline & $\begin{array}{l}\text { Transformador } \\
\text { subterrâneo a seco } \\
\text { DrySub }\end{array}$ & $\begin{array}{l}\text { Sistema Smart Grid de } \\
\text { gestão de energia }\end{array}$ & $\begin{array}{l}\text { Sistema de } \\
\text { Posicionamento } \\
\text { Dinâmico de } \\
\text { Plataformas Marítimas }\end{array}$ & Contatores Digitais \\
\hline $\begin{array}{l}\frac{\text { Gestão de }}{\text { ameaças e }} \\
\underline{\text { transformações }}\end{array}$ & $\begin{array}{l}\text { Elaboração de um } \\
\text { manual especifico do } \\
\text { equipamento que foi } \\
\text { entregue ao cliente. Por } \\
\text { outro lado, há muito } \\
\text { conhecimento e } \\
\text { experiências das } \\
\text { pessoas da Siemens e do } \\
\text { próprio cliente } \\
\text { participante do projeto, } \\
\text { sendo que estas } \\
\text { experiências e } \\
\text { conhecimentos não } \\
\text { foram passados aos } \\
\text { usuários finais do } \\
\text { produto, mantendo-se } \\
\text { como propriedade } \\
\text { intelectual, intangível, } \\
\text { de quem as tinha. } \\
\text { Destaca-se também a } \\
\text { geração de três patentes, } \\
\text { sendo que uma delas foi } \\
\text { depositada na Alemanha } \\
\text { porque a solução foi } \\
\text { gerada com a } \\
\text { participação de um } \\
\text { colaborado alemão, as } \\
\text { outras duas patentes } \\
\text { foram requeridas no } \\
\text { Brasil e no exterior. }\end{array}$ & $\begin{array}{l}\text { As soluções específicas } \\
\text { são muito complexas, } \\
\text { sendo impossível colocá- } \\
\text { las em manuais. O que se } \\
\text { faz é o compartilhamento } \\
\text { das experiências advindas } \\
\text { das integrações e das } \\
\text { implementações do } \\
\text { produto, caso a caso. Por } \\
\text { outro lado, os clientes são } \\
\text { muito experientes, } \\
\text { conhecedores destas } \\
\text { situações de contorno. } \\
\text { Vale pontuar também a } \\
\text { proteção por contratos de } \\
\text { confidencialidade entre } \\
\text { os parceiros de pesquisa e } \\
\text { desenvolvimento. Já na } \\
\text { etapa da entrega do } \\
\text { produto ao cliente, os } \\
\text { códigos são fechados, } \\
\text { indisponíveis. }\end{array}$ & $\begin{array}{l}\text { O sistema desenvolvido } \\
\text { dispensa manuais de uso, } \\
\text { seja porque as lógicas } \\
\text { estão protegidas, seja } \\
\text { porque as questões a } \\
\text { serem enfrentadas dizem } \\
\text { respeito às plataformas } \\
\text { petrolíferas em alto mar, } \\
\text { sendo o produto apenas } \\
\text { uma ferramenta à } \\
\text { disposição dos usuários. } \\
\text { Ressalta-se que a } \\
\text { propriedade intelectual } \\
\text { foi definida no contrato } \\
\text { estabelecido pela } \\
\text { parceria, baseado em } \\
\text { termos de } \\
\text { confidencialidade, o que } \\
\text { garantiu a cada parceiro a } \\
\text { propriedade sobre o seu } \\
\text { capital intelectual e pela } \\
\text { propriedade intelectual } \\
\text { desenvolvida pelas partes. } \\
\text { Além disso, o produto foi } \\
\text { protegido junto ao INPI } \\
\text { por meio de registro de } \\
\text { software. }\end{array}$ & $\begin{array}{l}\text { O produto é entregue } \\
\text { aos usuários com } \\
\text { manual de uso e um } \\
\text { treinamento básico, } \\
\text { inclusive em relação } \\
\text { aos modos de } \\
\text { parametrização do } \\
\text { software embutido } \\
\text { (firmware) e não } \\
\text { disponível aos } \\
\text { clientes. Destaca-se } \\
\text { também a geração de } \\
\text { uma patente de } \\
\text { desenho industrial e } \\
\text { uma patente de } \\
\text { invenção, sendo que a } \\
\text { primeira ficou } \\
\text { registrada em nome da } \\
\text { Siemens e a segunda } \\
\text { em nome do parceiro. } \\
\text { Decidiu-se em comum } \\
\text { acordo que as duas } \\
\text { empresas poderiam } \\
\text { comercializar o } \\
\text { produto, cada qual } \\
\text { com sua própria } \\
\text { marca. }\end{array}$ \\
\hline
\end{tabular}

Fonte: Autores

\section{CONSIDERAÇÕES FINAIS}

Os resultados demostraram que a subsidiária Siemens Brasil dispõe de uma capacidade dinâmica no que tange o desenvolvimento de novos produtos e processos, como evidenciado no Transformador DrySub, no Sistema Smart Grid, no Sistema de Posicionamento de Plataformas Marítimas e no produto Contatores Digitais.

Essa capacidade de desenvolvimento local possibilitou a acumulação, combinação, criação e compartilhamento de novos recursos tecnológicos entre a subsidiária, matriz, demais subsidiárias estrangeiras e parceiros externos adotando-se, para tal, processos intencionais e sistematizados de mapeamento do ambiente, aproveitamento das oportunidades e gestão de ameaças e transformações, conforme estabelecem Teece (2007) e Helfat et al. (2007).

\section{Sobre as Indagações do Protocolo de Pesquisa}

As indagações descritas na Tabela 2 passam a ser consideradas abaixo.

Sobre a 101: Os resultados evidenciam também que a Siemens Brasil dispõe de autonomia operacional nos projetos de P\&D para atender com agilidade as oportunidades e necessidade dos clientes mediante desenvolvimento interno e/ou cooperação tecnológica, corroborando com os preceitos de Ambos e Schlegelmilch (2007) e Bartlett e Ghoshal (1989) que destacam a importância da autonomia operacional para potencializar a 
capacidade da subsidiária estrangeira de explorar fontes externas de inovação e melhorar a sua base de recursos e desempenho, além de oferecer aos colaboradores a oportunidade local de abordar os problemas de forma criativa, estimulando a criatividade e a inovação organizacional.

Em relação a 102: Sobre as principais atribuições tecnológicas da Siemens Brasil, destacam (1) as intermediações entre os Centros de P\&D dos Estados Unidos e Alemanha, (2) a prospecção de oportunidades do mercado local com vocação natural para o segmento de energia, (3) a absorção de conhecimento local sólido e compartilhamento entre matriz e demais subsidiárias estrangeiras e o (4) estabelecimento de parceiras estratégicas, com acesso a mão de obra qualificada, de nível técnico a $\mathrm{PhD}$, possibilitando uma redução de custos via desenvolvimento de projetos conjuntos, além de acesso facilitado a fomentos públicos, com melhora na posição de custos. Dessa forma, constata-se que as atribuições da Siemens Brasil foram delegadas pela matriz de forma estratégica, resultando em intermediações e compartilhamentos de conhecimentos e tecnologias para a multinacional como um todo o que implica no desenvolvimento na subsidiária brasileira de competências difíceis de imitar e, portanto, geradoras de valor segundo Bouquet e Birkinshaw (2008) e Mudambi e Navarra (2004).

Sobre 103: Em relação a transferência reversa de ativos do conhecimento, nota-se que a Siemens Brasil recorre ao TECHNOWEB para transferir à matriz e demais subsidiárias estrangeiras os conhecimentos produzidos localmente, constatando-se um alinhamento aos preceitos de Monteiro e outros (2008), Mudambi e Navarra (2004) e Yang e outros (2008) no que tange a transferência de ativos do conhecimento a partir de uma base de conhecimento global compartilhada que gera reciprocidade e um fluxo frequente de conhecimento entre as subsidiárias e matriz.

Em relação às indagações 104 e 105: Sobre a abordagem da ambidesteridade de Birkinshaw e Gibson (2004) que estabelecem as funções de identificação de oportunidades (que permitem adaptabilidade) e de mobilização de recursos e processos para criar mais valor (que determinam o alinhamento), observou-se que na Siemens Brasil o mapeamento das oportunidades tecnológicas (adaptabilidade) ocorre a partir das parcerias tecnológicas, incluindo as interações com ICTs, clientes, fornecedores, empresas não concorrentes. Já a função de mobilização de recursos de inovação necessários às oportunidades (alinhamento) é implementada: (1) pelo Pictures of the Future (PoF), um mecanismo de inteligência e gestão tecnológica que avalia o desempenho dos projetos e estabelece priorizações; (2) pelo Siemens Technology Accelerator (STA), um departamento responsável por identificar e implementar estratégias de comercialização para inovações que não atuam no core de negócios; e (3) pela Technology to Business (TTB), uma unidade focada no investimento e incubação de startups de base tecnológica que possam contribuir para a expansão do portfólio da empresa.

\section{De Indagações a Proposições}

Analisando de forma agregada a atuação da Siemens Brasil no que tange a inovação, bem como os exemplos de desenvolvimento local analisados (quadros 3, 4 e 5), incluindo o Transformador DrySub, o Sistema Smart Grid, o Sistema de Posicionamento de Plataformas Marítimas e o produto Contatores Digitais, constatou-se que capacidade dinâmica de desenvolvimento tecnológico local da subsidiária brasileira (Siemens Brasil) foi potencializada pelas práticas de internacionalização da inovação delegadas e acompanhadas estrategicamente pela Matriz da Multinacional que incluem, especificamente (tabela 6):

(a) A autonomia em P\&D (BIRKINSHAW e outros, 2005) concedida à subsidiária para gerar de forma ágil desenvolvimentos locais potencializou o mapeamento do ambiente e a prospecção de parceiros estratégicos altamente complementares (Teece, 2007), tais como a matriz, as demais subsidiárias estrangeiras, as instituições científicas e tecnológicos nacionais, os fornecedores, os clientes, bem como empresas locais não concorrentes. Dessa forma, a Indagação 01 passa a ser apresentada como proposição $\mathrm{P}_{01}$, ou seja, a autonomia em $P \& D$ concedida à subsidiária potencializa 0 desenvolvimento de capacidades dinâmicas.

(b) As atribuições tecnológicas delegadas à subsidiária (Cantwell \& Mudambi, 2005; Noorderhaven \& Harzing, 2009), incluindo a intermediação entre unidades de P\&D, a prospeç̧ão de oportunidades, a absorção de conhecimento local e o estabelecimento de parcerias, potencializaram o aproveitamento de oportunidades (TEECE, 2007), incluindo o 
desenvolvimento e combinação de arranjos adequados ao relacionamento, como exemplo a criação de um centro de P\&D em cooperação com a PUC-PR. Assim, a Indagação 02 se transforma em proposição $\mathrm{P}_{02}$, ou seja, as atribuições tecnológicas delegadas à subsidiária potencializam o desenvolvimento de capacidades dinâmicas.

(c) A transferência reversa de ativos do conhecimento da subsidiária para à matriz e demais subsidiárias estrangeiras (Ambos \& Schlegelmilch, 2007; Keupp et al., 2011) potencializou a gestão da transformação do novo conhecimento (Teece, 2007) produzido localmente e sua posterior disseminação em rede global de conhecimento da multinacional, como exemplo destacam-se os desenvolvimentos locais analisados (quadros 3, 4 e 5), cujos conhecimentos gerados foram compartilhados com a matriz e demais subsidiárias estrangeiras a partir do TECHNOWEB. Dessa forma, a Indagação 03 passa a ser considerada Proposição 03 - $\mathrm{P}_{03}$, ou seja, a transferência reversa de ativos do conhecimento da subsidiária para a matriz e demais subsidiárias estrangeiras potencializa o desenvolvimento de capacidades dinâmicas.

(d) A ambidesteridade (funções de adaptação e alinhamento) (Birkinshaw \& Gibson, 2004) exercida pela subsidiária potencializou a gestão de ameaças e de proteção das parcerias (Teece, 2007), uma vez que foram adotadas estruturas internas de propriedade e também contratos formais de confidencialidade e proteção intelectual entre os parceiros e a Siemens Brasil considerando os desenvolvimentos locais analisados (quadros 3, 4 e 5), além disso, foram adotados mecanismos de governança para inteligência e gestão tecnológica (PoF), transferência e comercialização tecnológica (STA) e para investimento e incubação de startups (TTB). Assim, aceitam-se as Indagações 04 e 05, que se transformam em proposições $P_{04}$ e $P_{05}$, ou seja, as funções de adaptação e alinhamento exercidas pela subsidiária potencializam o desenvolvimento de capacidades dinâmicas.

Tabela 6. Capacidade dinâmica de desenvolvimento tecnológico local da Siemens Brasil.

\section{Capacidade dinâmica de desenvolvimento tecnológico} local

\begin{tabular}{|c|c|c|}
\hline & $\begin{array}{l}\text { Alteração da } \\
\text { base de recursos }\end{array}$ & $\begin{array}{l}\text { Desenvolvimento local de inovações, tais como o Transformador DrySub, o Sistema } \\
\text { Smart Grid, o Sistema de Posicionamento de Plataformas Marítimas e o produto } \\
\text { Contatores Digitais. }\end{array}$ \\
\hline$\underline{\text { Fundamentos }}$ & $\begin{array}{l}\text { Intencionalidade } \\
\text { estratégica }\end{array}$ & $\begin{array}{l}\text { As atribuições da Siemens Brasil foram delegadas pela matriz de forma estratégica, } \\
\text { envolvendo (1) as intermediações entre os Centros de P\&D dos Estados Unidos e } \\
\text { Alemanha, (2) a prospecção de oportunidades do mercado local com vocação natural } \\
\text { para o segmento de energia, (3) a absorção de conhecimento local sólido e } \\
\text { compartilhamento entre matriz e demais subsidiárias estrangeiras e o (4) } \\
\text { estabelecimento de parceiras estratégicas, visando acesso a mão de obra qualificada, } \\
\text { de nível técnico a PhD, possibilitando uma redução de custos via desenvolvimento } \\
\text { de projetos conjuntos, além de acesso facilitado a fomentos públicos, com melhora } \\
\text { na posição de custos. }\end{array}$ \\
\hline \multirow{3}{*}{$\frac{\text { Processos }}{\text { chave }}$} & $\begin{array}{l}\text { Mapeamento do } \\
\text { ambiente }\end{array}$ & $\begin{array}{l}\text { Autonomia em P\&D concedida à subsidiária para gerar de forma ágil } \\
\text { desenvolvimentos locais potencializou a prospecção de parceiros estratégicos } \\
\text { altamente complementares. }\end{array}$ \\
\hline & $\begin{array}{l}\text { Aproveitamento } \\
\text { das } \\
\text { oportunidades }\end{array}$ & $\begin{array}{l}\text { As atribuições tecnológicas delegadas à subsidiária, incluindo a intermediação entre } \\
\text { unidades de } \mathrm{P} \& \mathrm{D} \text {, a prospecção de oportunidades, a absorção de conhecimento local } \\
\text { e o estabelecimento de parcerias, potencializaram o aproveitamento de } \\
\text { oportunidades, incluindo o desenvolvimento e combinação de arranjos adequados ao } \\
\text { relacionamento. }\end{array}$ \\
\hline & $\begin{array}{l}\text { Gestão de } \\
\text { ameaças e } \\
\text { transformações }\end{array}$ & $\begin{array}{l}\text { A transferência reversa de ativos do conhecimento da subsidiária para à matriz e } \\
\text { demais subsidiárias estrangeiras potencializou a gestão da transformação do novo } \\
\text { conhecimento produzido localmente e sua posterior disseminação em rede global de } \\
\text { conhecimento da multinacional. Além disso, a ambidesteridade (funções de } \\
\text { adaptação e alinhamento) exercida pela subsidiária potencializou a gestão de } \\
\text { ameaças e de proteção das parcerias, uma vez que foram adotadas estruturas internas } \\
\text { de propriedade e também contratos formais de confidencialidade e proteção } \\
\text { intelectual entre os parceiros e a subsidiária. }\end{array}$ \\
\hline
\end{tabular}

Fonte: Autores. 
Em relação às limitações do estudo, destaca-se que as suas conclusões estão diretamente relacionadas ao caso analisado em profundidade. Dessa forma, as conclusões devem ser analisadas com parcimônia uma vez que essa opção metodológica não permite a realização de generalizações acerca das conclusões obtidas. Quanto às propostas de estudos futuros, propõe-se uma pesquisa quantitativa inferencial sobre o impacto da internacionalização da inovação (a autonomia em P\&D, as atribuições tecnológicas e a transferência reversa de ativos do conhecimento)

\section{REFERÊNCIAS}

Altmann, R. M. (2005). As Multinacionais Brasileiras com Plantas Industriais no Exterior: Configuração das Operações Internacionais. Dissertação de mestrado, Programa de PósGraduação em Engenharia de Produção, Escola Politécnica da Universidade de São Paulo, São Paulo, Brasil.

Ambos, B., \& Schlegelmilch, B. B. (2007). Innovation and control in the multinational firm: a comparison of political and contingency approaches. Strategic Management Journal, 28, 473-486.

Andersson, U., Forsgren, M., \& Holm, U. (2002). The strategic impact of external networks: subsidiary performance and competence development in the multinational corporation. Strategic Management Journal, 23, 979-996.

Bailyn, L. (1985). Autonomy in the industrial Rand-D Lab. Human Resource Management, 24 (2), 129-146.

Bartlett, C. A., \& Ghoshal, S. (1989). Managing Across Borders: The Transnational Solution. Harvard Business School Press, Boston.

Birkinshaw, J., \& Gibson, C. (2004). Building Ambidexterity into an Organization. MIT Sloan Management Review, 45 (4), 47-55.

Birkinshaw, J., Hood, N., \& Young, S. (2005). Subsidiary entrepreneurship, internal and external competitive forces, and subsidiary performance. International Business Review, 14 (2), 227-248.

Birkinshaw, J. (1996). How multinational subsidiary are gained or lost. Journal of International Business Studie, 27 (3), 496-495. sobre a capacidade dinâmica de desenvolvimento local, tendo-se como objeto de estudo o universo de subsidiárias de multinacionais brasileiras que atuam em economias desenvolvidas e em desenvolvimento.

Em complemento ao referido acima, as proposições 01 a 05, já evidenciadas cientificamente, poderão ser transformadas em pressupostos, precisando, para tal, que um estudo mais amplo seja realizado, por exemplo, com utilização do método quantitativo como complemento a este.

Bouquet, C., \& Birkinshaw, J. (2008). Weight versus voice: How foreign subsidiaries gain attention from corporate headquarters. Academy of Management Journal, 51 (1).

Cantwell, J., Dunning, J. H., \& Lundan, S. M. (2010). An evolutionary approach to understanding international business activity: The co-evolution of MNEs and the institutional environment. Journal of International Business Studies, 41 (4) 567-586.

Cantwell, J., \& Piscitello, L. (2007). Attraction and deterrence in the location of foreign-owned $R \& D$ activities: the role of positive and negative spillovers. International Journal of Technological Learning, Innovation and Development, 1 (1), 83-111.

Cantwell, J., \& Mudambi, R. (2005). MNE competence-creating subsidiary mandates. Strategic Management Journal, 26 , p. 1109-1128.

Collis, D., \& Montgomery, C. (1995). Competing on resources strategy in the 1990s. Harvard Business Review, p. 118-128.

Criscuolo, P., \& Narula, R. (2007). Using multi-hub structures for international R\&D: organizational inertia and the challenge of implementation. Management International Review, 47( ), 1-22.

Doz, Y., Santos, J., \& Williamson, P. (2001). From Global to Metanational. Harvard Business School Press, Boston.

Dunning, J. H. (2006). Towards a paradigm of development: implications for the determinants of international business activity. Transnational Corporations, 15 (1), 173-227.

Dunning, J. H., \& Lundan, S. M. (2010). The institutional origins of dynamic capabilities in 
multinational enterprises. Industrial and Corporate Change, 19 (4), 1225-1246.

Dunning, J. H., \& Lundan, S. M. (2008). Multinational Enterprises and the Global Economy. Edward Elgar Publishing Limited, United Kingdom.

Eden, L. (2009). Letter from editor-in-chief: reverse knowledge transfers, culture clashes and going international. Journal of International Business Studies, 40 (2), 177-180.

Eisenhardt, K. M., \& Martin, J. A. (2000). Dynamic capabilities: what are they? Strategic Management Journal, 21, 1105-1121.

Flick, U. (2009). Uma introdução à pesquisa qualitativa: Bookman.

Frost, T., Birkinshaw, J., \& ENSIGN, P. (2002). Centers of Excellence in Multinational Corporations. Strategic Management Journal, 23, 997-1018.

Frost, T.S., \& Zhou, C. (2005) R\&D co-practice and 'reverse' knowledge integration in multinational firms. Journal of International Business Studies, 36 (6), 676-687.

GIL, A. C. (2002). Métodos e técnicas de pesquisa social: Atlas.

Gnyawali, D., Singal, M., \& Mu, S. (2009). Knowledge ties among subsidiaries in MNCs: a multilevel conceptual model. Journal of International Management, 15 (4), p. 387-400.

Helfat, C. E., Finkelstein, S., Mitchell, W., Peteraf, M., Singh, H., Teece, D., \& Winter, S. G. (2007). Dynamic Capabilities: Understanding Strategic Change. In. Organizations. Oxford: Blackwell Publishing.

Keupp, M, M., Palmié, M., \& Gassmann, O. (2011). Achieving Subsidiary Integration in International Innovation by Managerial "Tools". Management International Review, 51 (2), 213-239.

Lehrer, M., Asakawa, K., \& Behnam, M. (2011). Home base-compensating R\&D: Indicators, public policy, and ramifications for multinational firms. Journal of International Management, 17 (1), 42-53.

Manolopoulos, D., Söderquist, K. E., \& Pearce, R. (2011). Coordinating decentralized research and development laboratories: A survey analysis. Journal of International Management, 17 (2), 114-129.

Marin, A., \& Bell, M. (2010). The local / global integration of MNC subsidiaries and their technological behaviour: Argentina in the late 1990s. Research Policy, 39 (7), 919-931.

Martins, G. de A. (2006). Estudo de caso: Uma estratégia de pesquisa: Editora Atlas.

Miles, M. B., \& Huberman, A. M. (1984). Qualitative data analysis: an expanded sourcebook Thousand Oaks: Sage Publications.

Monteiro, L. F., Arvidsson, N., \& Birkinshaw, J. (2008). Knowledge flows within multinational corporations: Explaining subsidiary isolation and its performance implications. Organization Science, 19 (1), 90-107.

Mudambi, R. (2008). Location, control and innovation in knowledge intensive industries. Journal of Economic Geography, 8 (5), 669-725.

Mudambi, R., \& Navarra, P. (2004). Is knowledge power? Knowledge flows, subsidiary power and rentseeking within MNCs. Journal of International Business Studies, 35, 385-406.

Nobel, R., \& Birkinshaw, J. (1998). Patterns of control and communication in international research and development units. Strategic Management Journal, 19, 479-498.

Noorderhaven, N., \& Harzing, A. W. (2009). Knowledge-sharing and social interaction within MNEs. Journal of International Business Studies, 40 (5), 719-741.

Penrose, E. (1959). The theory of the growth of the firm. Oxford: Basil Blackwell.

Peteraf, M. A. (1993). The cornerstones of competitive advantage: a resource-based view. Strategic Management Journal, 14 (3), 179-191.

Phene, A., \& Almeida, P. (2008). Innovation in multinational subsidiaries: the role of knowledge assimilation and subsidiary capabilities. Journal of International Business Studies, 39 (5), 901-919.

Prahalad, C. K., \& Hamel, G. (1990). The Core Competence of the Corporation. Harvard Business Review, p. 79-91.

Rabbiosi, L. (2011). Subsidiary roles and reverse knowledge transfer: An investigation of the effects of coordination mechanisms. Journal of International Management, 17 (2), 97-113.

Richardson, R. J. (1999). Pesquisa Social: Métodos e Técnicas: Atlas. 
Siemens. (2014). Relatório anual e de Sustentabilidade. Disponível em: < http://relatorioanual2014.com.br/downloads/sieme ns-relatorio-anual-2014.pdf >. Acesso em Outubro de 2015.

Sirkin, H. L., Hemerling, J. W., \& Bhattacharya, A. K. (2008). Globality: challenger companies are radically redefining the competitive landscape. Strategy \& Leadership, 36 (6), p. 36-41.

Teece, D. J. (2014). A dynamic capabilities-based entrepreneurial theory of the multinational enterprise, Journal of International Business Studies, 45 (1), 8-37.

Teece, D. J. (1980). Economics of scope and the scope of the enterprise. Journal Economic Behavior and Organization, 1 (3), 223-247.

Teece, D. J. (2007). Explicating dynamic capabilities: the nature and microfoundations of (sustainable) enterprise performance. Strategic Management Journal, 28, 319-1350.

Teece, D. J. (1986). Profiting from technological innovation: Implications for integration, collaboration, licensing and public policy. Research Policy, 15 (6) 285-305.
Teece, D. J. (1982). Towards an economic theory of the multiproduct firm. Journal Economic Behavior Organization, 3 (1), 39-63.

Teece, D. J., PISANO, G., \& SHUEN, A. (1997). Dynamic Capabilities and Strategic Management. Strategic Management Journal, 18 ( ), 509-533.

Vieira, M. M. F. (2004). Por uma Boa Pesquisa (Qualitativa) em Administração. In M. M. F. Vieira \& D. M. Zouain (Eds.), Pesquisa qualitativa em administração: FGV Editora.

Winter, S. G. (2003). Understanding Dynamic Capabilities. Strategic Management Journal, 24 ( ), 991-995.

Yang, Q., Mudambi, R., \& Meyer, K. (2008). Conventional and reverse knowledge flows in multinational corporations. Journal of Management, 34 (5), 882-902.

Yiu, D. W., Lau, C. M., \& Bruton, G. D. (2007). International venturing by emerging economy firms: The effects of firm capabilities, home country networks, and corporate entrepreneurship. Journal of International Business Studies, 38 (4), 519-540.

\section{SOBRE OS AUTORES}

- Antonio de Sant'Anna Limongi França - Pós doutorando na Faculdade de Engenharia de Produção da Escola Politécnica da Universidade de São Paulo - USP, São Paulo, (Brasil). E-mail: antonio.limongi@hx8.com.br Orcid id: https://orcid.org/0000-0001-9551-8352

- Emerson Antonio Maccari - Doutor em Administração pela Universidade de São Paulo - USP, São Paulo, (Brasil). Professor na Universidade Nove de Julho - UNINOVE, São Paulo. E-mail: emersonmaccari@gmail.com Orcid id: https://orcid.org/0000-0001-7085-224X

- Priscila Rezende da Costa - Doutora em Administração pela Universidade de São Paulo - USP, São Paulo, (Brasil). E-mail: priscilarezende@yahoo.com.br Orcid id: https://orcid.org/0000-0002-7012$\underline{0679}$ 


\title{
DYNAMIC CAPABILITIES AND INNOVATION INTERNATIONALIZATION: THE CASE SIEMENS BRAZIL
}

\author{
Antonio de Sant'Anna Limongi França, Emerson Antonio Maccari, Priscila Rezende Da Costa \\ Escola Politécnica da Universidade de São Paulo, São Paulo, (Brazil) \\ Universidade Nove de Julho, São Paulo, (Brazil)
}

\begin{tabular}{l}
\hline ARTICLE DETAILS \\
\hline Article history: \\
Received: 26 june 2018 \\
Accepted: 17 december 2018 \\
Available online January: 01th 2019 \\
Double Blind Review System \\
Scientifc Editor \\
Ilan Avrichir \\
\hline
\end{tabular}

\section{Keywords:}

Internationalization

Dynamic Capabilities

Subsidiary

Multinational

\begin{abstract}
The overall objective was to analyze how the process of developing dynamic capabilities can be enhanced by the practices of internationalization of innovation include, in particular: (a) autonomy in R \& D granted to the subsidiary of a multinational, (b) the delegated technological assignments the subsidiary of a multinational, (c) reverse transfer subsidiary of knowledge assets to the array and other foreign subsidiaries of a multinational and (d) the ambidesteridade (adaptation and alignment functions) exerted by the subsidiary of a multinational. To this end, it carried out a qualitative research and adopted as a method to study the case of Siemens Brazil. Specifically, analyzed in depth the mechanisms and development interfaces of the following innovations of Siemens Brazil: (1) Underground Transformer Dry DrySub, (2) System Smart Grid power management, (3) Dynamic Positioning System Offshore platforms and (4) Contactors Digital. The survey findings reveal relevant scientific contributions with regard to understanding the fundamentals and key processes of the dynamic of technological development site of a subsidiary, and synergies towards the internationalization practices of innovation of a multinational.
\end{abstract}

(C) 2018 Internext | ESPM. All rights reserved!

Para citar este artigo:

Limongi França, A., Maccari, E., \& Costa, P. (2019). Capacidades Dinâmicas e Internacionalização da Inovação: O Caso Siemens Brasil. Revista Eletrônica de Negócios Internacionais, 14(1), 76-92. doi:https://doi.org/10.18568/internext.v14i1.463 